\title{
REPUBLICA DE COLOMBIA REVISTA DE LA ACADEMIA COLOMBIANA de Ciencias Exactas, Físicas y Naturales
}

\author{
Publicacion del Ministerio de Educacion Nacional
}

\section{E D I T O R I A L}

\section{BREVE CONSIDERACION}

La misión de la ciencia como imprescindible función social se remonta a todas las civilizaciones que han existido en el mundo, durante el transcurso de su historia, de acuerdo con la proporción cultural de cada una de ellas.

Aristóteles el Estagirita, tres siglos antes de Jesucristo, clasificó la ciencia tan racionalmente que, aún hoy en día, sus conceptos nos sirven de base para orientar la investigación cientifica. El gran filósofo en sus escritos acroamáticos, o sea, aquellos en donde plasmó sus conocimientos técnicos, dividió esta materia en las siguientes ramas: teórica, práctica $y$ poética; la última acepción ha sido objeto de muchas controversias, pero, según nuestro parecer, no se debe desechar porque el sentimiento poético es el estímulo y el ideal que existe, de hecho, en la curiosidad del hombre al buscar la verdad de los fenómenos naturales.

La ciencia práctica, según el pensamiento aristotélico, coincide con la que denominamos en la actualidad aplicada, producto natural de la teórica; por consiguiente, el objeto singular de esta última comprende la búsqueda de los conocimientos verdaderos para evitar posteriores errores que vendrian a perjudicar los hechos humanos.

De acuerdo con lo expuesto, la Academia Colom. biana de Ciencias está dirigiendo sus actividades hacia ese sentido, obteniendo, por natural consecuencia, los éxitos deseados, a pesar de ser muchas las aspiraciones que se pretenden y que, confiando, se lograrán paulatinamente gracias al entusiasmo, conocimientos y buena voluntad de sus miembros $y$ de todos los gentiles amigos, repartidos en las diferentes latitudes del globo.

Presentamos a continuación algunos importantes actos de la Academia que se han llevado a cabo recientemente y que, además de reafirmar nuestro pensamiento, exaltan las personalidades nacionales, y los acontecimientos cientificos que nos deben enorgullecer.

$$
\text { * * * }
$$

Homenaje al sabio Francisco José de Caldas. Próximamente el público podrá admirar y servirse de una bella estampilla nacional, representativa del sabio Caldas en el momento culminante de su preclara vida de hombre de ciencia, o sea aquel en que, desde las alturas andinas, solitario, con sus modestos aparatos, descubrió el método para medir las alturas, de acuerdo con la ebullición del agua. En la interpretación del dibujo - admirablemente ejecutado por el maestro Luis Alberto Acuña-se puso interés especial en reproducir to más exactamente la interpretación del hecho, teniendo en cuenta todos los detalles históricos y cientificos que se pudieron recoger. A la par, con la estampilla, y según el mismo modelo, el señor Bernardo Vieco está elaborando un precioso relieve que, esperamos, tendrá muy buena acogida por parte de los admiradores de nuestro sabio.

El origen de la estampilla se remonta exclusivamente a la iniciativa de la Academia, -y, posteriormente, a la buena acogida que tuvo por parte del Gobierno Nacional-, cuando se aprobó unánimemente por la corporación la proposición presentada en ese sentido por el distinguido académico doctor Luis María Murillo, en la sesión correspondiente al dia 12 de septiembre de 1950.

Adhiriéndose a esta feliz iniciativa, la Dirección de la Revista, dedica el presente número al gran sabio colombiano.

"Resolución No 7. - La Academia Colombiana de Ciencias Exactas, Físico-Químicas y Naturales, considerando: $1^{\circ-}$ Que el sabio Francisco José de Caldas, partícipe y mártir de nuestra Independencia, realizó estudios e investigaciones relacionadas con el conocimiento de la astronomía, la física y la naturaleza de nuestro suelo; 2 ?-Que por sus concepciones sobre la nivelación de las plantas que se cultivan en la vecindad del 
ecuador puede considerársele como a uno de los creadores de las ciencias ecológicas; $3^{\circ}$-Que su descubrimiento del método de medición de alturas por medio de la ebullición del agua fue una de las más grandes y oportunas contribuciones en orden al conocimiento de la altimetría de las montañas; $4^{\circ}-$ Que tanto por la vida inmaculada del sabio, su permanente amor al estudio y sus investigaciones en las ciencias naturales, su vida es un ejemplo constante para la juventud, y $5^{\circ}-$ Que el descubridor del hipsómetro es desconocido no sólo en el mundo científico extranjero sino en su propia patria, RESUELVE: - ARTICULO 1\%-Solicitar respetuosamente del Excelentísimo Señor Presidente de la República y del Señor Ministro de Correos y Telégrafos que ordenen una emisión de timbres postales que consagre el descubrimiento del hipsómetro por medio de un dibujo con la imagen del sabio en trance del descubrimiento mencionado y con la siguiente leyenda: "DESCUBRIMIENTO DEL HIPSOMETRO POR CALDAS, 1799"; ARTICULO 2\%-Remítanse sendas copias de esta Resolución al Excelentísimo Señor Presidente de la República, a los Señores Ministros de Correos y Telégrafos y de Educación Nacional y a la Academia Nacional de Historia. - Comuníquese y cúmplase. Dada en Bogotá. a 12 de septiembre de 1950. - (Fdo.) BELISARIO RUIZ WILCHES, presidente. - ALFREDO D. BATEMAN, secretario".

"MINISTERIO DE CORREOS Y TELEGRAFOS. Decreto número 003260 de 1950 (octubre 25). - Por el cual se ordena una emisión de estampillas de correos. EL PRESIDENTE DE LA REPUBLICA DE COLOMBIA en uso de sus facultades legales, y considerando: Que el sabio Francisco José de Caldas, partícipe y mártir de nuestra Independencia, realizó estudios e investigaciones relacionadas con el conocimiento de la astronomía, la física y la naturaleza del suelo colombiano, y que en las especies postales deben conmemorarse los hechos históricos, DECRETA: - ARTICULO 10-Ordénase la emisión de tres millones $(3.000 .000)$ de estampillas de correos de valor facial de treinta centavos $(\$ 0.30)$, las que llevarán la imagen del sabio Caldas y la siguiente leyenda: "DESCUBRIMIENTO DEL HIPSOMETRO POR CALDAS, 1799". - ARTICULO $2^{\circ}$ Las especies a que se refiere el artículo anterior tendrán valor postal por tiempo indefinido. - Comuníquese y cúmplase. - Dado en Bogotá, a 25 de octubre de 1950. (Fdo.) LAUREANO GOMEZ. - El Ministro de Hacienda y Crédito Público, (Fdo.) RAFAEL DELGADO BARRENECHE. - El Ministro de Correos y Telégrafos, (Fdo.) JOSE TOMAS ANGULO".

$$
\text { * * * }
$$

Nuevos académicos. - Las labores de la Academia se iniciaron en el presente año con la designación de catorce nuevos académicos; la entidad está segura de haber aportado, con el ingreso del nuevo contingente, una fuerza estimuladora para sus actividades, ya que ellos, por si solos, han escrito una brillante hoja de servicios en los diferentes campos de la cultura y de la investigación cien. tífica.

Sus nombres son:

José Ignacio Ruiz, Director del Instituto Geográfico "Agustín Codazzi”;

Santiago Triana Cortés, distinguido médico, catedrático titular de la Facultad Nacional de Medicina;
Jorge Bejarano, ex-ministro de higiene en varias ocasiones y hombre dinámico que ha beneficiado al pais con invaluables servicios;

Ernesto Guhl, geógrafo y explorador, conocedor profundo del territorio patrio;

Andrés Soriano Lleras, médico de brillante trayectoria, especialmente en lo relacionado con las ciencias naturales y biológicas;

Luis Augusto Cuervo, historiador consagrado a todas las actividades culturales, incluyendo aquellas que han tenido relación con el desenvolvimiento cientifico de Colombia;

Vicente Pizano Restrepo, ex-rector de la F'acultad de Matemáticas e Ingeniería de la Universidad Nacional y profesor titular de la misma;

Roberto Sarmiento Soto, geólogo, vinculado especialmente con las investigaciones petroleras;

Leopoldo Guerra Portocarrero, Decano de la Fa. cultad de Ciencias de la Universidad Nacional;

R. P. Lorenzo Uribe, S. J., botánico que viajó recientemente, en comisión especial, a España para recopilar el herbario de Mutis;

Luis Duque Gómez, Director del Museo Etnológico Nacional;

Jorge Ancízar Sordo, Direotor del Laboratorio Químico Nacional;

J. Hernando Ordónez, prófesor de la Facultad Nacional de Medicina y fundador de los "Anales de la Sociedad de Biología", y

Gilberto Botero Restrepo, distinguido geólogo y paleontólogo.

$$
\text { * * * }
$$

Museo de Ciencias Naturales. - La Academia Colombiana de Ciencias, en su calidad de cuerpo consultivo del Gobierno Nacional, se ha interesado por la creación del Museo de Ciencias Naturales y Materias Primas, teniendo en cuenta el beneficio científico y cultural que vendría a mejorar la prestancia colombiana ante el mundo intelectual.

Esta intervención académica, ha causado profunda satisfacción por el interés personal que al respecto manifestó el Excelentisimo Señor Presi. dente de la República Doctor Laureano Gómez.

$$
\text { * * * * }
$$

Centro de Actividades Geográficas del Instituto Panamericano de Geografía e Historia. - Ultimamente se han venido reuniendo en el Observatorio Astronómico Nacional un grupo de destacados caballeros con el objeto de crear y organizar sistemáticamente los estudios e investigaciones geográficas de acuerdo con los requerimientos del Instituto Panamericano de Geografía e Historia con sede en México. 


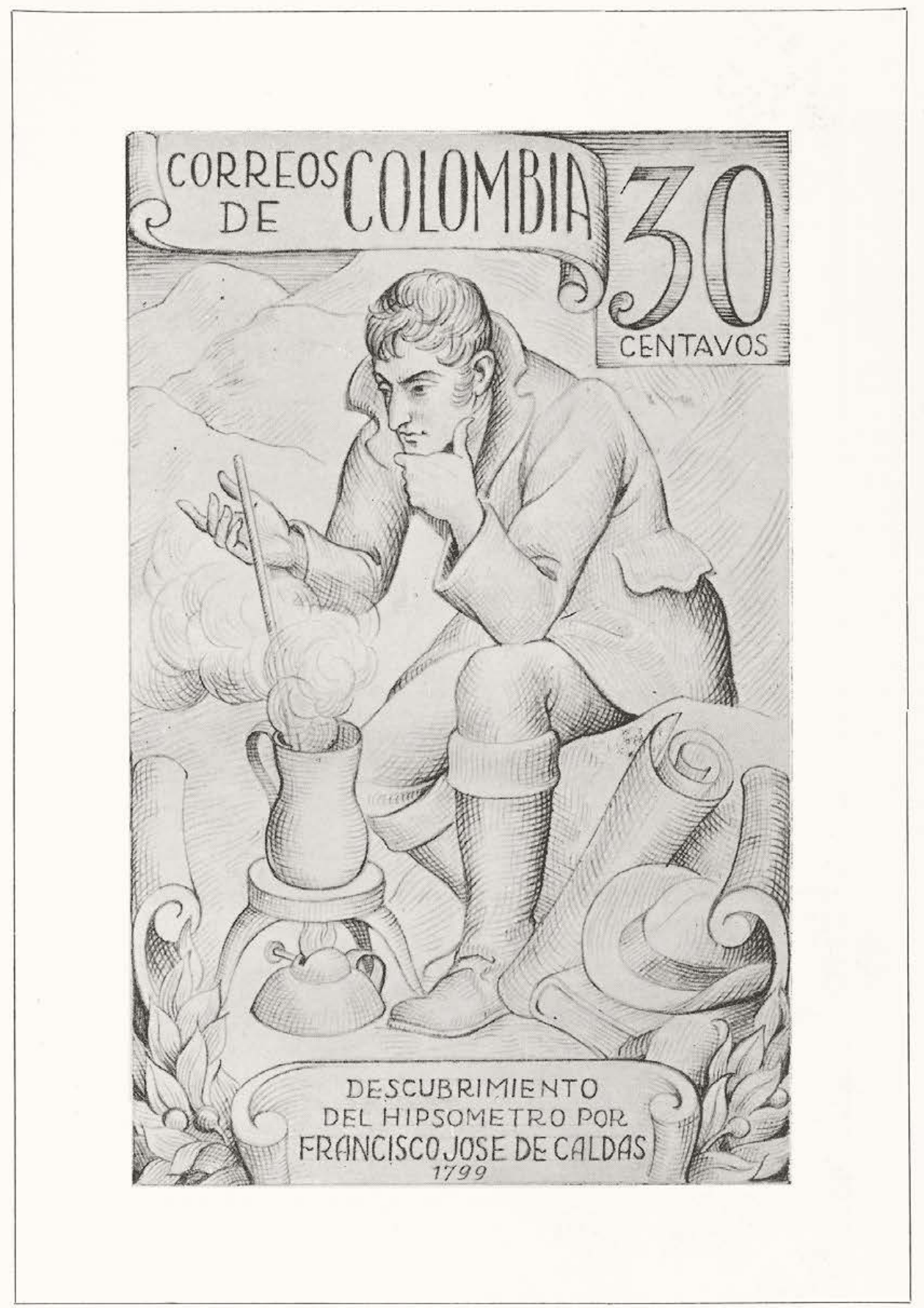

